\title{
Hydraulic Runner Design Method for Lifetime
}

\author{
Michel Sabourin $^{1}$, Denis Thibault ${ }^{2}$, David-Alexandre Bouffard ${ }^{1}$ and Martin Lévesque ${ }^{3}$ \\ ${ }^{1}$ Alstom Power and Transport Canada Inc \\ 1350 chemin St-Roch, Sorel-Tracy (Québec), J3P 5P9, Canada, \\ michel.sabourin@power.alstom.com,david-alexandre.bouffard@power.alstom.com \\ ${ }^{2}$ Hydro-Québec, Institut de Recherche d'Hydro-Québec \\ 1800 boul. Lionel-Boulet, Varennes (Québec), J3X 1S1, Canada, \\ thibault.denis@ireq.ca \\ ${ }^{3}$ École Polytechnique de Montréal, Département de génie mécanique \\ C.PP.6079, succ. Centre-ville, Montréal (Québec), H3C 3A7, Canada, \\ martin.levesque@polymtl.ca
}

\begin{abstract}
Quest for reliability of hydraulic runners is a concern for all mature electricity producers. The fatigue damage caused by dynamics loads is frequently the root cause of runner failure. This paper presents the damage tolerance approach based on fracture mechanics as the method chosen by Alstom and Hydro-Québec to predict effects of damage on runner lifetime and consequently to be use as a design method. This is sustained by a research on fracture mechanics properties of runner materials and by recommendations on the strategy to define a safety margin for design. The acquired knowledge permits to identify potential improvement of the runner lifetime without significant cost increase, like being more specific on some chemical composition or heat treatment.
\end{abstract}

Keywords: Runner Design, Fatigue, Lifetime, Fracture Mechanics, Material Properties, Runner Failure

\section{Introduction}

For countries with mature economy, many hydroelectricity producers are already involved in major upgrade and rehabilitation programme. They have extensive experience with operation and maintenance of hydraulic units, realizing the large economical advantage of reliable units. They also face new conditions of operation imposed by the energy market and the growing part of the wind or solar equipment dependant on variable environment condition to produce and needing network compensation sustained by hydroelectric equipment. This combination, needs for reliability and increase of dynamic loads, challenges the engineer to design runners for the expected lifetime simulating real loading conditions.

It is well known that, apart from the infant mortality of runner due to a systematic design or fabrication error, cyclic loads are an important cause of runner failure. The traditional fatigue approach is based on a statistical analysis of test coupons. It does not take into account the actual state of the component, existing defects or residual stress. Moreover, there is a recognized need to predict the remaining life of existing runner taking into account new turbine operation pattern imposed by the electrical network management. With all these requirements in mind, Alstom and Hydro-Québec oriented their research on the implementation of fracture mechanics as a design and assessment tool for hydraulic runners.

Various data are needed to conduct a fracture mechanics analysis of a component such as:

1. Component geometry including existing flaws,

2. Residual stresses in the component,

3. Properties of materials composing the component,

4. Expected static and cyclic loads.

The use of fracture mechanics in runner design is based on a damage tolerance approach. It means that a defect of a given initial size at one particular location in a component is tracked throughout the expected life of the runner. Three possibilities exist:

1. This defect does not evolve and remains at the initial size,

2. This defect grows during the expected life but does not cause the failure,

3. This defect grows and the part fails before the expected life. 
Therefore, to establish the fracture mechanics at the level of design tool some challenges have to be managed. The traditional static approach is well guided, there are some codes like ASTM or ASME that guide the designer on material properties and safety factors to use. The same does not exist when the cyclic loads has to be introduced in the design process.

The first challenge is then to obtain the fracture mechanics material properties and the residual stresses of the component considered. Therefore, conducting a research on material properties is necessary. The second challenge is to determine a calculation method that manages adequate safety factors. These two challenges are the topic of this article and will be treated in the following paragraphs. At the end, the new developed knowledge gives the opportunity to runner lifetime improvement with manufacturing parameters optimization.

\section{Research on material properties}

\subsection{Bibliographic research}

Due to the relatively young nature of the fracture mechanics science and also of the alloys often used in runner manufacturing such as ASTM A743M Grade CA6NM, information available on material properties are less than 30 years old. In fact most of the knowledge has been cumulated since the eighties.

Several parameters differentiate the material property test results of stainless steels over those years. Some tests are conducted in normal air, some in water, and some other in dry air. The stress ratio, $R$, qualifying a loading cycle is also an important parameter. The manufacturing process, like casting, forging or plate can also have a significant outcome on fracture mechanics properties of a given steel. Even the variability of chemistry of each alloy can have an effect. Obviously, the superposition of these results presents a given level of scatter. Figures 1 to 4 illustrate this phenomenon with some results collected in literature, ref. [1] to [14].

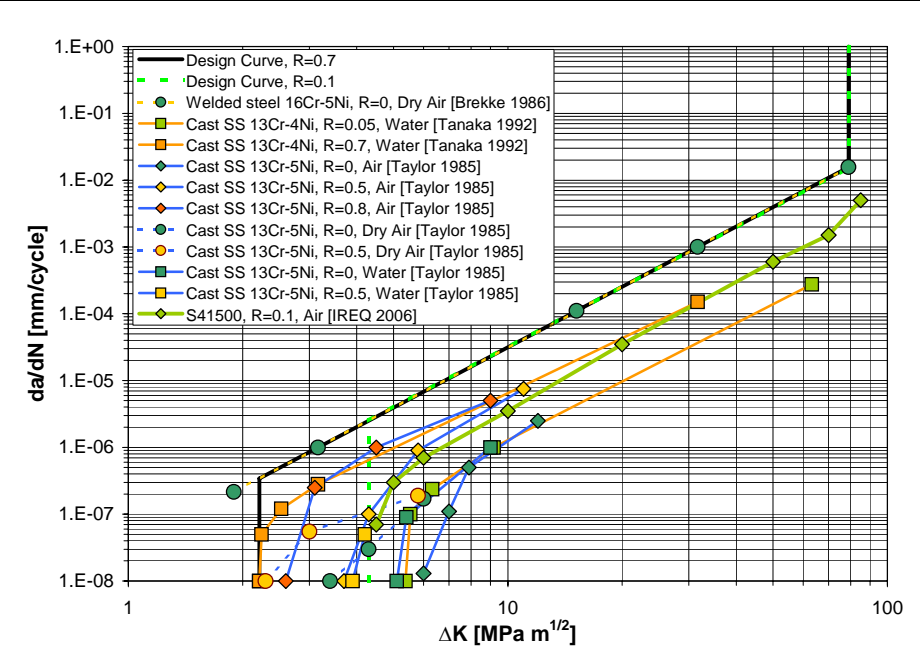

Fig. 1 Crack growth data for different martensitic stainless steels similar to CA-6NM

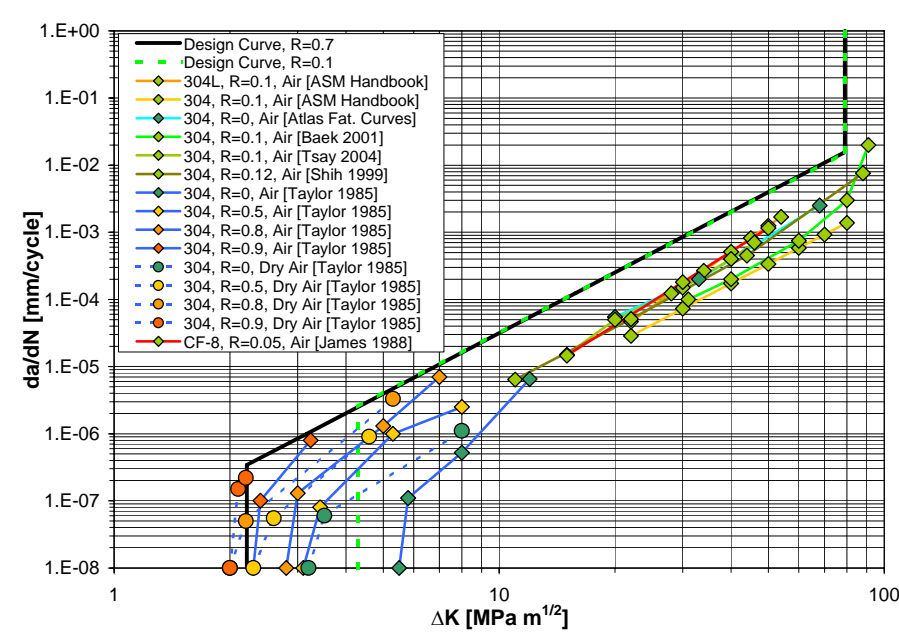

Fig. 3 Crack growth data for different austenitic stainless steels similar to $\mathrm{CF}-8$ and to $\mathrm{CF}-3$

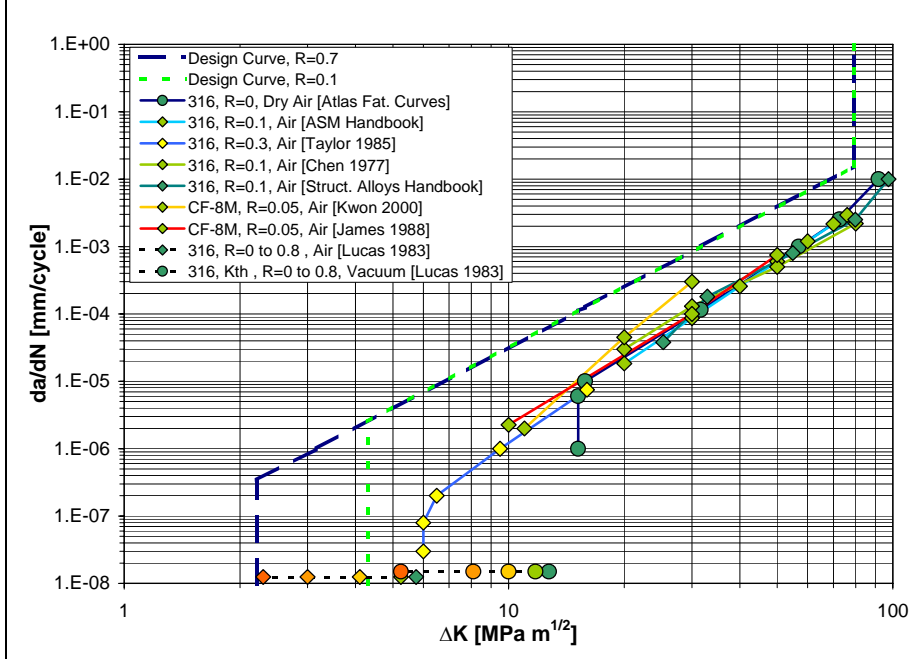

Fig. 2 Crack growth data for different austenitic stainless steels similar to the CF-8M

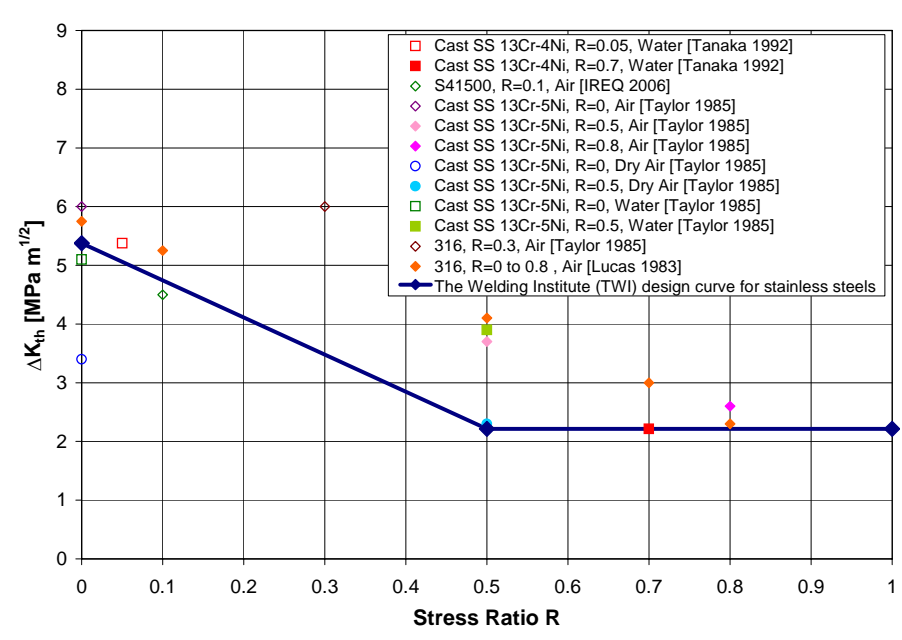

Fig. 4 Crack propagation threshold $\Delta \mathrm{K}$ th as a function of the stress ratio $\mathrm{R}$ 
Nevertheless, all these data allowed establishing a set of material properties safe for design, the resulting curve is also shown in figures for reference.

The scatter of the fracture material properties is demonstrated in a publication [15] comparing standard fatigue curves of two steels using the same ASTM grade CA6NM designation. On Figure 5, the divergence between curves obtained for CA6NM

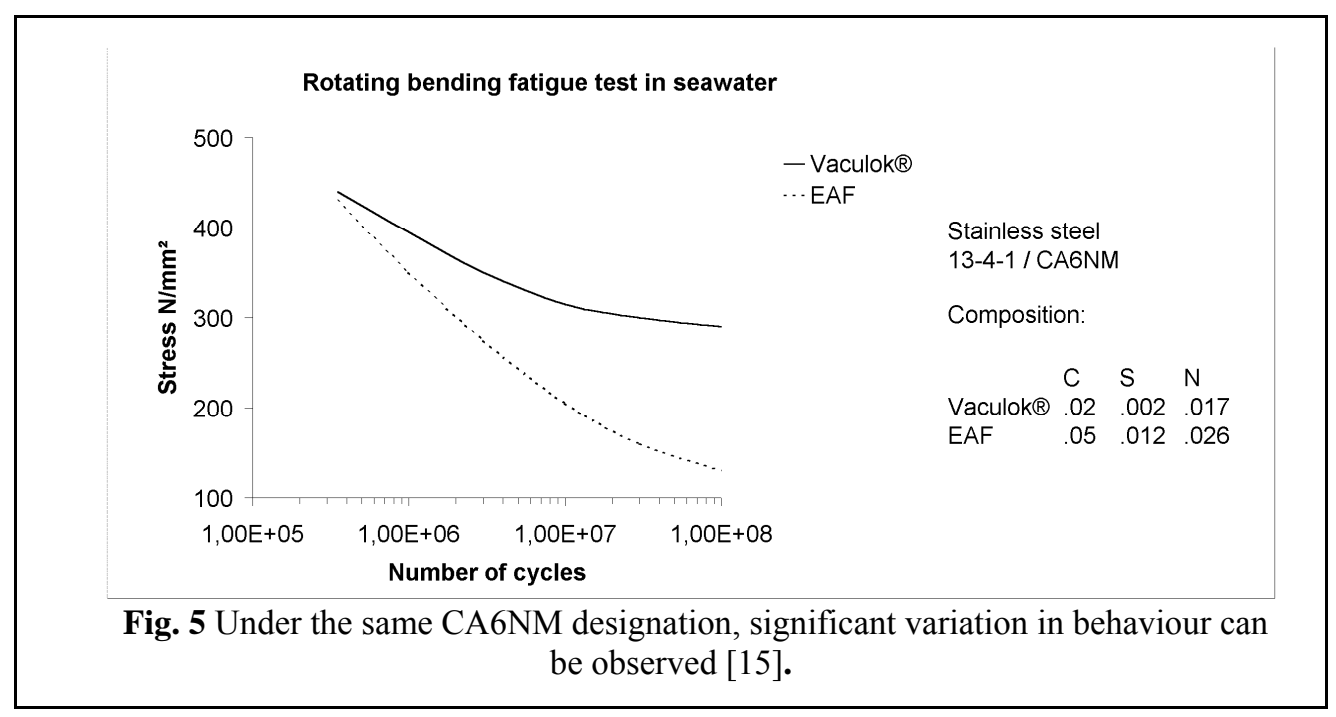

stainless steel demonstrates that all steels do not behave identically in fatigue. Then, there is a need to dig more deep and to understand what are the properties of the actual steels we now use in runner manufacturing.

\subsection{Comprehensive research program in fracture mechanics}

For all these reasons, Alstom and Hydro-Québec decided to launch a research program on the characterization of fracture mechanics properties of steel used in hydraulic runners. This research, in progress since 2004, aims to study the homogeneous fabrication of runners made from CA6NM base alloy. After completing the development of a testing protocol, see reference [16], two commercial foundries produced stainless steels, identified as steels A and B, bought under the same technical specification, were tested [17] to obtain fracture mechanics properties.

Table 1 shows the similar chemical compositions for both steels. Table 2 points out the higher strength and hardness of steel B. The similarity of standard properties is not surprising, the two suppliers had to face the same requirements. We can only observe that steel B presents a higher yield strength and metallographic examination [17] indicates a finer grain size probably due to the heat treatment. Also, Charpy impact test results are similar for both steels, over 160 Joules at $0^{\circ} \mathrm{C}$, which is quite satisfactory.

Table 1 Chemical compositions are similar for both steels. [17]

\begin{tabular}{|l|c|c|c|c|c|c|c|c|}
\hline Steel & $\mathbf{C}$ & $\mathbf{M n}$ & $\mathbf{S i}$ & $\mathbf{S}$ & $\mathbf{P}$ & $\mathbf{C r}$ & $\mathbf{N i}$ & $\mathbf{M o}$ \\
\hline A & 0,02 & 0,66 & 0,59 & 0,008 & 0,031 & 13,04 & 4,07 & 0,53 \\
\hline B & 0,03 & 0,57 & 0,37 & 0,02 & 0,02 & 12,68 & 4,03 & 0,67 \\
\hline CA-6NM & 0.06 & $1.0 \mathrm{max}$ & $1.0 \mathrm{max}$ & $\begin{array}{c}0.03 \\
\max \end{array}$ & $\begin{array}{c}0.04 \\
\max \end{array}$ & $11.5-14$ & $3.5-4.5$ & $0.4-1.0$ \\
\hline
\end{tabular}

Table 2 Standard mechanical properties are slightly different. Steel B is higher in yield strength. [17]

\begin{tabular}{|c|c|c|c|c|c|c|}
\hline Steel & $\begin{array}{c}\text { Yield } \\
\text { strength } \\
(\mathbf{M P a})\end{array}$ & $\begin{array}{c}\text { Tensile } \\
\text { strength } \\
\mathbf{( M P a )}\end{array}$ & $\begin{array}{c}\text { Young's } \\
\text { Modulus } \\
\mathbf{( G P a )}\end{array}$ & $\begin{array}{c}\text { Elongation } \\
\mathbf{( \% )}\end{array}$ & $\begin{array}{c}\text { Area } \\
\text { reduction } \\
\text { (\%) }\end{array}$ & $\begin{array}{c}\text { Brinel } \\
\text { Hardness }\end{array}$ \\
\hline A & 626 & 791,2 & 204,3 & 27,8 & 56,8 & 253 \\
\hline B & 763,2 & 836,7 & 206,8 & 27 & 58,8 & 268 \\
\hline ASTM A- & $550 \mathrm{~min}$ & $755 \mathrm{~min}$ & --------- & $15 \mathrm{~min}$ & $35 \mathrm{~min}$ & $285 \max$ \\
\hline
\end{tabular}

Fracture toughness of both steels has also been measured according to ASTM E-1820 procedure. From results presented in Table 3 and Figure 6, it can be observed that steel A displays a better fracture toughness than steel B. 
Table 3 Fracture toughness of grade CA6NM stainless steels A and B [17]

\begin{tabular}{|c|c|c|}
\hline $\begin{array}{c}\text { Stainless } \\
\text { Steel }\end{array}$ & $\begin{array}{c}J_{Q} \\
\left(\mathrm{~kJ} / \mathrm{m}^{2}\right)\end{array}$ & $\begin{array}{c}K_{I C} \\
(\mathrm{MPa} \sqrt{ } \mathrm{m})\end{array}$ \\
\hline A & 387 & 295 \\
\hline B & 290 & 257 \\
\hline
\end{tabular}
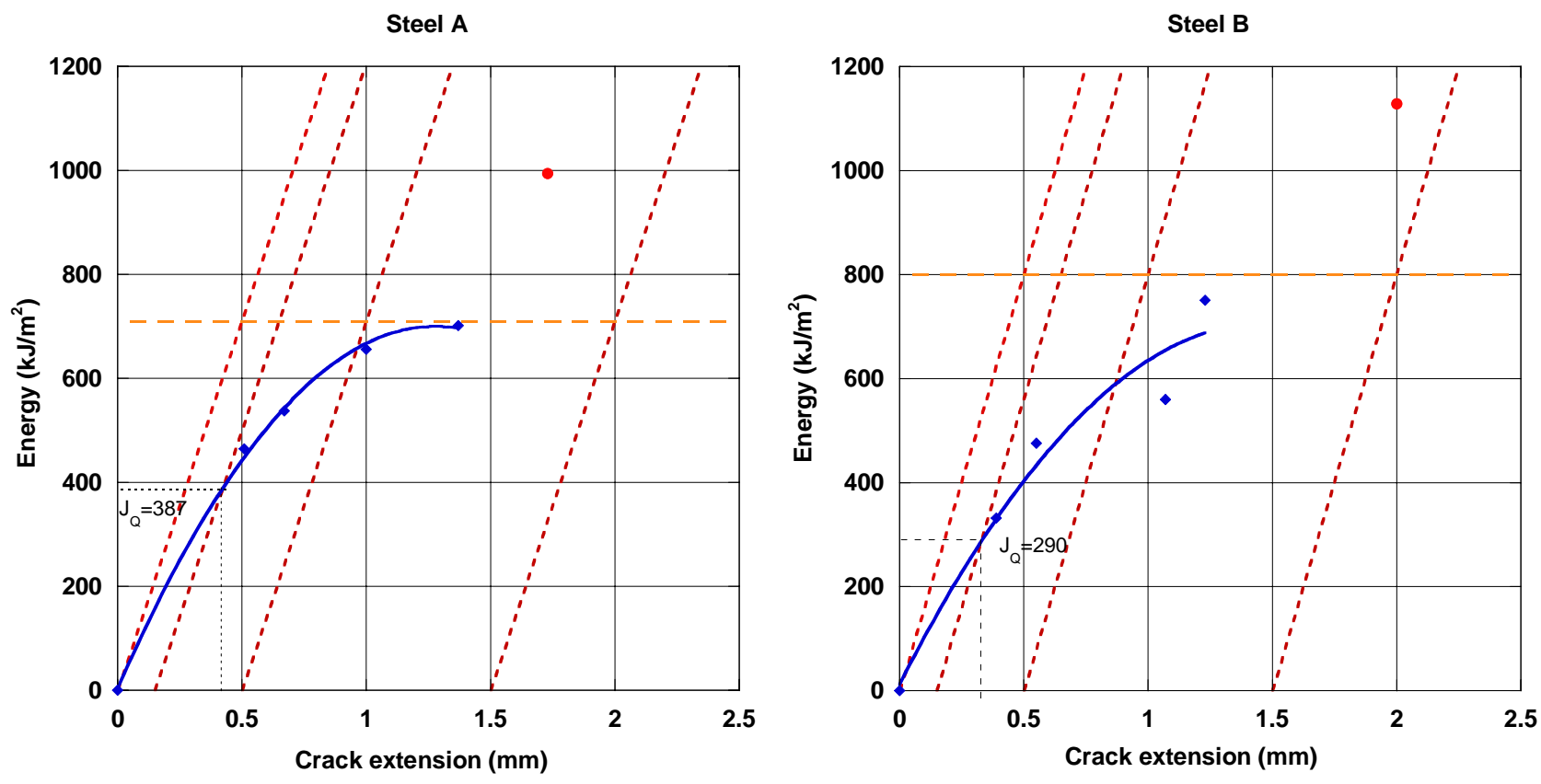

Fig. $6 J-R$ curves for grade CA6NM stainless steels A and B with blue dots only considered, as per ASTM E-1820 procedure [17]

Over the last year, this work has been continued at École Polytechnique de Montréal adding new results for $R=0.7$, see Figure 7. This demonstrates again the importance of the foundry process on the fatigue quality of steels. Despite very similar properties, the fracture mechanics testing of both steels gave a surprising result. The propagation rates are 2 times lower for steel A than for steel $\mathrm{B}$ at stress ratio $R=0.1$, and at $\mathrm{R}=0.7$, the threshold of propagation is lower for steel $\mathrm{B}$. Figure 7 depicts the comparison of the measured fracture mechanics properties for both steels. While steel B presented interesting yield strength properties, it does not appear ideal for runner longevity.

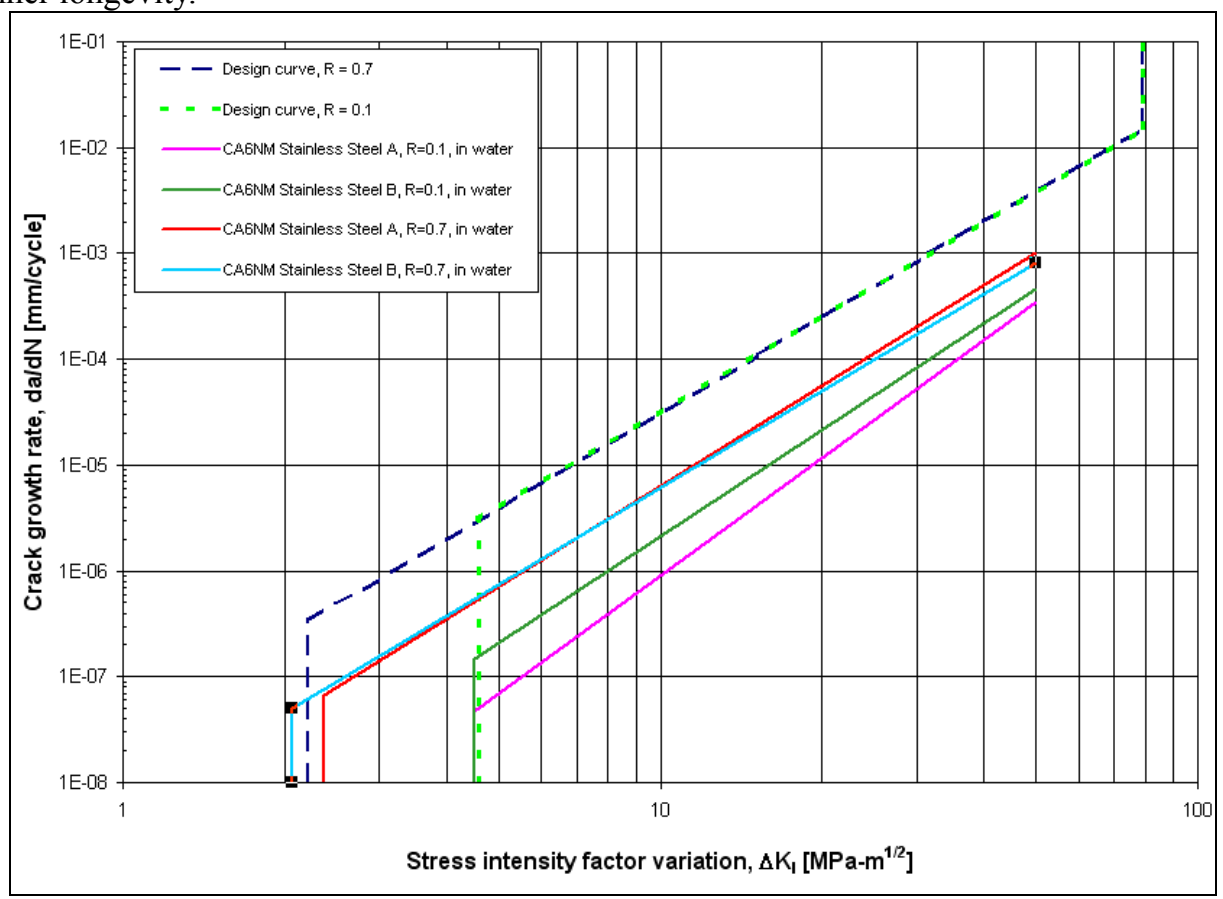

Fig. 7 Paris diagram obtained from properties of steels A and B 
In continuation with the studies on base metal properties, Hydro-Québec characterized the fatigue crack growth rate in 410NiMo welds, chemically homogeneous with CA6NM. Preliminary results shows that post-weld heat treatment greatly improves fatigue crack growth behavior of 410NiMo welds. After PWHT, 410NiMo samples tend to have the same behavior as the base metal while before PWHT they showed a fatigue crack growth rate significantly higher than PWHT samples. Interestingly, the threshold of propagation of PWHT 410NiMo is better than base metal.

Fracture toughness testing of as-welded and PWHT joints will also be investigated. We already know from Charpy V-notch results accumulated over the years, that resilience is systematically lower in the weld than in the base metal. In 2008, Alstom asked to École de Technologie Supérieure to study the variables influencing Charpy impact test results in 410NiMo welds using the FCAW process. In the CA6NM base metal, heat-treated in accordance with ASTM A-743, the Charpy impact test results can be over $160 \mathrm{~J}$. In the $410 \mathrm{NiMo}$ weld metal; Charpy impact test values are much lower, about $30 \mathrm{~J}$ without heat treatment and $40 \mathrm{~J}$ with heat treatment.

The heat affected can itself be separated in different zones depending on the thermal history that it experienced during welding. Carrouge [18] and Thibault et al. [19] identified five zones of the HAZ in 13Cr-4\%Ni (CA6NM grade) soft martensitic stainless steel. To correctly characterize these ones, tests should be done on samples that have experienced the same thermal history. This has still to be done.

Casas et al. in [20] tested fracture toughness at the junction of CA6NM base metal with 410NiMo FCAW welds without PWHT. The average value obtained from 3 coupons tested is $89 \mathrm{MPa} \mathrm{m}{ }^{1 / 2}$, which is significantly less than the $278 \mathrm{MPa}^{1 / 2}$ found for the tempered CA6NM base metal. The authors explained this low toughness by "inclusions of oxides arising from the waste from tubular wire used".

The degradation of the fracture toughness properties in the welds or caused by welding is not well understood and can reduce significantly the runner lifetime. This phenomenon, although highly complex in nature, represents a promising research orientation.

\subsection{Factors influencing fracture mechanics properties and their impact on lifetime}

Three fracture mechanics material properties are used in the calculation of runner lifetime. They are:

1. The threshold stress intensity factor, defining the boundary between the presence and absence of crack propagation.

2. The crack propagation rate for a given stress intensity factor variation.

3. The material toughness, defining the stress intensity to which the crack will grow at the sound velocity and cause the immediate brittle failure of the part.

These factors are dependant of the nature of the material. For a runner, three types of material can be identified:

1. Base material, that constitutes each separated components of the runner

2. Filler metal used for welding

3. Material in the heat-affected zone which possesses its own properties and can itself be separated in five different materials

Even with an homogeneously fabricated runner, the chemical composition and the thermal history are different for these three materials and impact significantly their mechanical and fatigue properties.

The observations made on CA6NM type material from the measurements presented in [17] and presented in Fig. 7 suggest that any effort to increase the yield strength of a martensitic stainless steel by an optimal combination of chemistry and heat treatment is not optimal for lifetime. In that sense, a tendency can be observed: higher carbon content and low temperature PWHT can increase yield strength at the detriment of the lifetime. The effect of carbon and PWHT will be studied more rigorously in a research project to come.

\subsection{Impact of residual stresses in fracture mechanics analysis}

Crack growth behaviour of stainless steels can be modeled by the Paris equation, which relates the fatigue crack growth rate $d a / d N$ to the stress intensity factor range $\Delta K$ as

$$
\frac{d a}{d N}=C(\Delta K)^{n}
$$

where $a$ is the crack length, $N$ is the number of cycles, and $C$ and $n$ are material constants. The stress intensity factor range, $\Delta K$, is the difference between the maximum and minimum stress intensity of a load cycle, $\Delta K=K_{\max }-K_{\min }$.

Solely based on equation (1), it would be coherent to consider stress intensity as the main factor influencing crack propagation. However, the stress ratio, $R$ (ratio between minimum and maximum applied load), can also affect the crack growth rate, as an increase in $R$ mostly results in an increase of crack growth for a given stress intensity range. See Figure 3 that illustrates the influence of stress ratio on crack growth rate $d a / d N$ and crack propagation threshold $\Delta K_{t h}$, which is the variation of stress intensity where the incipience of crack growth is observed. 


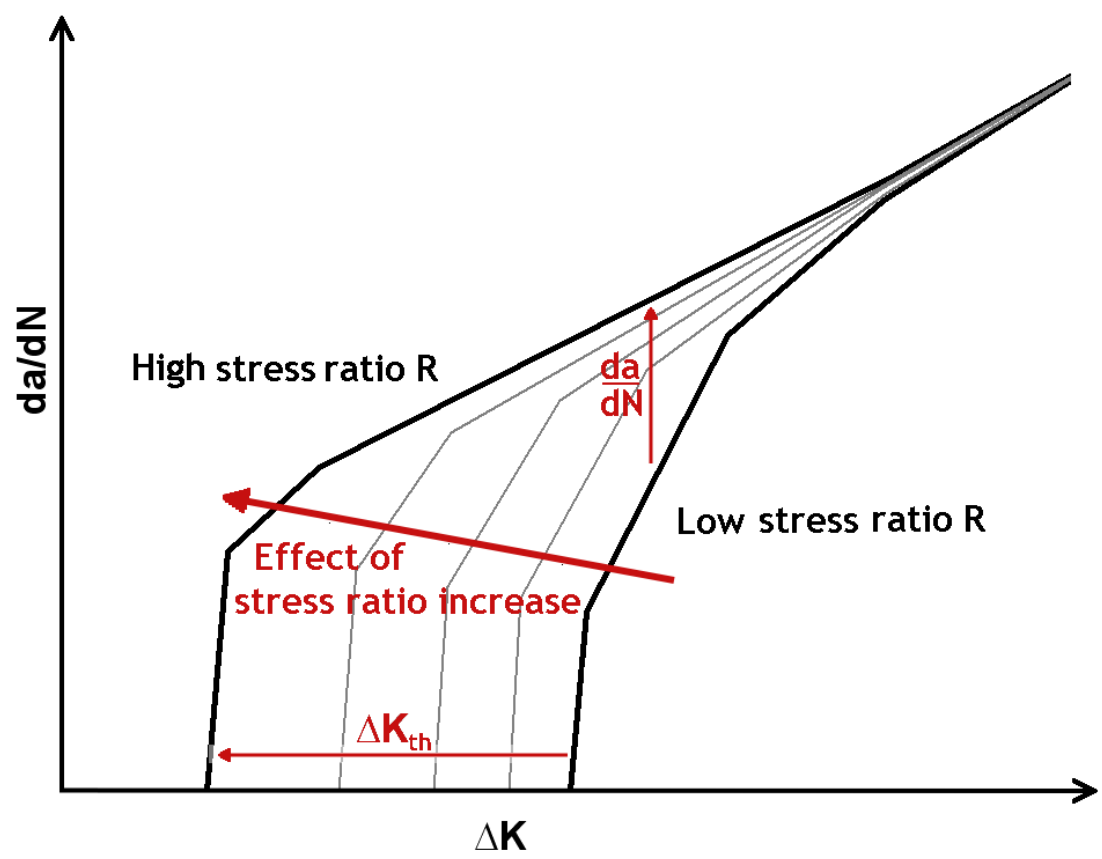

Fig. 8 Influence of stress ratio on crack growth rate and propagation threshold

This effect is caused by two distinct phenomena:

- Inherent material dependency of crack growth rate on $R$

- Crack closure effect

Crack closure implies that only a portion of a loading cycle leads to crack propagation, primarily the tensile portion. Since Elber pointed out this phenomenon [21] and attributed it to residual tensile deformation left along the crack flanks, many other closure mechanisms have been identified e.g. oxide-induced closure [22], etc.. Fatigue cracks can then be fully or partly closed while the material is still subjected to tensile stresses. To take the crack closure effect into consideration, it is appropriate to identify an opening stress intensity value Kop representing the minimum stress intensity required to force a crack fully open. Crack is closed for any stress intensity below $K_{o p}$ and the fully applied stress intensity range, $\Delta K$, cannot contribute to crack propagation. To take this into consideration, it is best to consider $\Delta K_{\text {eff }}$ instead of $\Delta K$ in equation (1), where

$$
K_{\text {eff }}=K_{\max }-K_{\text {opp }}
$$

However when analysing welded joints, one has to consider that they can be subjected to tensile residual stresses of yield stress magnitude. The presence of these tensile residual stresses promotes a completely open fatigue crack at all stages of loading. If tensile residual stresses are high, $K_{\min }$ is greater than $K_{o p}$ throughout the load cycle; the full stress intensity range can therefore contribute to crack propagation; crack closure is absent. Thus, for highly tensile residual stresses, fatigue life of as-welded components is governed by the total stress range fluctuation and becomes independent of the stress ratio or crack closure. This results in an increase of crack growth rate for a given stress intensity range and a reduction in crack propagation threshold, $\Delta K_{t h}$. Excessive tensile residual stresses can also initiate unstable fracture in materials with low-fracture toughness. The tensile residual stress field can be combined with in-service stresses to promote brittle failure. Such a brittle failure can occur during the manufacturing process, well before the first turbine operation load cycle. Therefore, tensile residual stresses can lead to premature fatigue failure or brittle failure of a welded component such as hydraulic runners, if not taken into account during design and inspection.

\subsection{Research on residual stress}

Residual stresses are present in every metallic component and are the result of the manufacturing process. The most common way to manufacture a hydraulic runner is by welding an assembly of components, made from various processes such as casting, forming, welding and machining. The sequence of the runner manufacturing process and the complexity of the physical phenomena involved make prediction of residual stress levels through calculations methods difficult and frequently unreliable. For a rigorous and repeatable manufacturing process, the residual stress field is quite reproducible. Some measurement methods have been demonstrated to be reliable means to assess residual stress fields. This has in fact been confirmed by measurements taken on the surface of several runners manufactured in Alstom facilities.

To use a damage tolerance approach, the residual stress level has to be known, not only everywhere on the surface, but also in the volume of the runner.

The hole drilling method is a standard ASTM method [23] for measuring residual stresses on a flat surface. It consists in a hole drilling at the centre of a special rosette strain gage. During drilling, stress relaxation occurs and deformation measurements allow for $2 \mathrm{D}$ residual stresses to be calculated.

For internal volume residual stress, Alstom and Hydro-Québec, conjointly with École Polytechnique de Montréal and École de 
Technologie Supérieure, implemented the contour method developed by Prime [24]. This method is suitable for evaluation of residual stresses in a welded T-Joint. Moisan [25] implemented this method that involved the manufacturing of T-Joint samples in dimensions representative of those found in typical runners. Then, these samples were cut by electro-erosion method with respect to a relevant plane. A very precise Coordinates Measuring Machine measured the displacements on the cut faces. Then, an inverse method using finite element simulation was used to obtain the residual stress profile.

Since, a series of measurements with varying sample dimensions, manufacturing processes and material compositions have documented a database that can be referenced for future analysis.

The combination of this destructive testing method with the standard ASTM method [23] applied on the runner surfaces validate the residual stress level to use in damage tolerance analysis.

\section{Designing with fracture mechanics and lifetime prediction}

Assuming that all the required data to conduct a fracture mechanics analysis available, the question remains: How to manage an adequate safety margin?

The use of a damage tolerance approach for lifetime prediction as design tool for hydraulic runner faces various challenges. As this method is based on the propagation of an existing flaw, the probability of flaws to remain in the runner at the delivery from the manufacturer has to be considered.

In all cases, the approach is to calculate the critical defect size that would bring runner failure at the minimum required lifetime. The best practice in the industry is to repair all linear defects that can be found before delivery. In fact, the larger a critical defect is, the easier it is to detect by usual inspection means and thus, the safer a design is. Therefore, the safety factor, in such a case, is the difference between the critical defect size and the defect detection threshold of the inspection methods. Thus, material properties used in a damage tolerant design should be the properties actually measured in the labs for the material.

On the other hand, when designing a partial penetration weld, the heel of the weld will constitute the critical defect. The probability of existence of this defect is one hundred percent. Therefore, it is appropriate to use and additional safety factor on the material properties. As such, the Alstom design curve has propagation rates significantly higher than the ones observed on real material. On Fig. 7, the propagation rate of the design curve is many time the real propagation rate measured on two steels.

Often, the safety margin of a particular design is a combination of the two approaches:

1. A critical defect size larger than the larger detected defect.

2. Conservative material properties.

Of course, the calculation protocol, the considered dynamic load pattern and its interaction with the material behaviour, the hypothesis made on the propagation direction and many other variables can influence the result.

\section{Conclusion}

From a design perspective, the elegance of the damage tolerance based on fracture mechanics approach lies in its ability to link the design to the fabrication process and the inspections; this is the designer point of view. For the operator, the interest resides in the relation between the in-service part with all its defects and expected operating condition.

Alstom and Hydro-Québec are currently involved in a large research program aimed at improving the comprehension of the different parameters influencing runner lifetime. As part of this investigation, the residual stress measurements and the fracture mechanics properties measurements brought useful data, making the lifetime calculation more reliable.

It has also been observed that the material type and the manufacturing process have a definitive effect on lifetime and can be optimized through the mastering of standard parameters such as chemical composition and heat treatment, often without any cost increase. This optimization must also be extended to the procurement process, in order to include the complete history of the component.

A design method involving a damage tolerance approach based on fracture mechanics has still to be refined but is becoming the most pertinent way to obtain a reliable runner and to understand how to improve its realization.

\section{Nomenclature}

$\begin{array}{ll}a & \text { Crack length }[\mathrm{mm}] \\ J_{Q} & \text { Fracture toughness }\left[\mathrm{J} \cdot \mathrm{m}^{-2}\right] \\ K_{I C} & \text { Fracture toughness }\left[\mathrm{MPa} \cdot \mathrm{m}^{1 / 2}\right] \\ N & \text { Number of load cycles } \\ \Delta K & \text { Stress intensity factor range }\left[\mathrm{MPa} \cdot \mathrm{m}^{1 / 2}\right] \\ \Delta K_{t h} & \text { Crack propagation threshold }\left[\mathrm{MPa} \cdot \mathrm{m}^{1 / 2}\right]\end{array}$

$\begin{array}{cl}C, n & \text { Material constants } \\ K & \text { Stress intensity factor }\left[\mathrm{MPa} \cdot \mathrm{m}^{1 / 2}\right] \\ K_{o p} & \text { Crack opening stress intensity }\left[\mathrm{MPa} \cdot \mathrm{m}^{1 / 2}\right] \\ R & \text { Stress ratio } \\ \Delta K_{e f f} & \text { Effective stress intensity factor range }\left[\mathrm{MPa} \cdot \mathrm{m}^{1 / 2}\right]\end{array}$

\section{References}

[1] Brekke H., 1986, "Design and material quality for high head turbines," IAHR 13th Symposium, Montreal, Canada.

[2] Chen W.C., Liu H.W., 1977, "Fatigue crack growth at elevated temperature 316 stainless steel and H-13 steel," National Aeronautics and Space Administration (NASA), Syracuse, USA.

[3] Gavenda D.J., Michaud W.F., Galvin T.M., 1996, "Effects of thermal aging on fracture toughness and charpy-impact strength of stainless steel pipe welds," Report NUREG/CR-6428, US Nuclear Regulatory Commission, Washington, USA, 72 p.

[4] James L.A., Mills W.J., 1988, "Fatigue-crack propagation and fracture toughness behavior of cast stainless steels," 
Engineering Fracture Mechanics, Vol. 29, No. 4, pp. 423-434.

[5] Kwon J.D., Park J.C., Lee Y-S., 2000, “An inverstigation of the degradation characterictics for casting stainless steel, CF8M, under high temperatures," Nuclear Engineering and Design, Vol. 198, pp. 227-240.

[6] Lucas G., Ritchie R., 1983, "Damage analysis and fundamental studies," Proceedings of the 2nd workshop on fusion environment sensitive flow and fracture processes, US Departement of Energy, Washington, USA.

[7] Mills W.J., 1997, "Fracture toughness of type 304 and 316 stainless steels and their welds," The Institute of Materials and ASM International, International Materials Reviews, Vol. 42, No. 2, pp. 45-82.

[8] MILLS W.J., 1988, "Heat-to-heat variations in the fracture toughness of austenitic stainless steels," Engineering Fracture Mechanics, Vol. 30, pp. 469-492.

[9] Shih Y.S., Chen J.J., 1999, “The frequency effect on the fatigue crack growth rate of 304,” Nuclear Engineering and Design, Vol. 191, pp. 225-230.

[10] Sokolov M.A., Robertson J.P., Snead L.L., 2002, "Fracture toughness characterization of 304L and 316L austenitic stainless steels and alloy 718 after irradiation in high-energy, mixed proton/neutron spectrum, Effects of Radiation on Materials," 20th International Symposium, American Society for Testing and Materials, West Conshohocken, USA.

[11] Structural Alloys Handbook, Edition 1996, Edited by John M. Holt, CINDAS/Purdue University, West Lafayette, USA, 1996.

[12] Tanaka H., 1992, "Studies on dynamic stress of runners for the design of 760 meter head pump-turbines," IAHR 16th Symposium, Sao Paulo, Brazil.

[13] Taylor D., 1985, “A compendium of fatigue thresholds and growth rates,” Engineering Materials Advisory Services, Warley, England, 389 pp.

[14] Tsay L.W., Liu Y.C., Young M.C., 2004, "Fatigue crack growth of AISI 304 stainless steel welds in air and hydrogen," Materials Science and Engineering, Vol. A 374, pp. 204-210.

[15] K. Uimonen, 1984, Master Thesis, Tampere University of Technology, Finland. Courtesy of Lokomo Steels.

[16] Lanteigne, J., Sabourin, M., Bui-Quoc, T. and Julien, D., 2007, “A Comprehensive Research Program on Crack Propagation Characteristics of the Base Material used in Hydraulic Turbine Runners," WaterPower XV, Chattanooga, USA.

[17] Lanteigne J., Sabourin M., Bui-Quoc T. and Julien D., 2008, “The Characteristics of the Steels used in Hydraulic Turbine runners," IAHR 24th Symposium on Hydraulic Machinery and Systems, Foz do Iguassu, Brasil.

[18] Carrouge D., 2003, "Phase transformations in welded supermartensitic stainless steels." PhD Thesis University of Cambridge. [19] Thibault D., Thomas M., Bocher P., 2009, "Residual stress and microstructure in welds of 13\%Cr-4\%Ni martensitic stainless steel," J. Mater. Process Tech, Vol. 209, No. 4, pp. 2195-2202.

[20] Casas W.J.P., Henke S.L., Novicki N., 2009, "Fracture toughness of Ca6NM alloy, quenched and tempered and of its welded joint without PWHT," Welding International, Vol. 23, No. 3, March 2009, pp. 166-172.

[21] Elber W., 1970, "Fatigue crack closure under cyclic tension," Engineering Fracture Mechanics, vol. 2, pp. 37-45.

[22] Suresh S., 1998, Fatigue of materials, 2nd ed. Cambridge University Press.

[23] ASTM, "Standard Test Method for Determining Residual Stresses by the Hole Drilling Strain-Gage Method E837-99, 10 pp. 1999.

[24] Prime M. B, 2001, "Cross-sectional mapping of residual stresses by measuring the surface contour after a cut," Journal of Engineering Materials and Technology, Vol. 123, pp. 162-168.

[25] Moisan É., Sabourin M., Bernard M. and Bui-Quoc T., 2006, "Residual Stress Measurement in Hydraulic Turbine Welded Joints," IAHR 23th Symposium on Hydraulic Machinery and Systems, Yokohama, Japan.

[26] Thibault D., Bocher P., Thomas M., Gharghouri M., Côté M., 2009, "Residual stress characterization in low transformation temperature $13 \% \mathrm{Cr}-4 \% \mathrm{Ni}$ stainless steel weld by neutron diffraction and the contour method," Mat. Sci. Eng. A. 